\title{
A manera de presentación
}

En este segundo número de la Revista de Museología Kóot, el Museo Universitario de Antropología de la UTEC, se complace en ofrecer a los lectores seis artículos de destacados investigadores nacionales, quienes, cada uno en sus áreas científicas, nos hacen reflexionar sobre la museografía, la arquitectura, la antropología, la arqueología, la historia, la museología y la conservación. Kóot es entretenimiento científico e incentivo para investigar nuestra realidad cultural, pero también es el medio por el cual se divulga el producto de las investigaciones que directa o indirectamente, tiene que ver con ese amplio espectrum de la cultura.

El arquitecto Víctor Manuel Rivas Merino, nos ofrece un interesante artículo en donde analiza la obra arquitectónica del arq. Armando Sol Estévez quien titula: El Legado gráfico arquitectónico de Armando Sol. Rivas parte que la obra arquitectónica de Sol, precisamente en la parte urbana de lo que hoy es el centro histórico del gran San Salvador, se aprecia tanto la arquitectónica como el material gráfico teniendo su propio sello de identidad. Rivas es de la opinión de que muchos de los salvadoreños desconocen tal legado hasta el punto de ignorarlo, y, por consiguiente, tiende a desaparecer, volviéndose en algunos casos en una pérdida irreversible. Y Rivas afirma que "esa falta de identidad y desvaloración hacia el patrimonio cultural edificado, ha dado como resultado el saqueo, el vandalismo y la destrucción de muchas de las edificaciones hechas por el arquitecto Sol". Son estructuras que se niegan a morir, como legado de un romántico pasado y de los tiempos de bonanza que los vieron erigirse.

Por su parte, la restauradora del Museo Nacional de Antropología, "Dr. David J. Guzmán" y egresada de la licenciatura en Antropología, Beatriz Castillo, nos ofrece un apuntado artículo que titula: La conservación de bienes culturales muebles en El Salvador, una tarea por hacer. La autora nos recuerda que la conservación y la restauración han tomado un lugar preponderante para la cultura en todo el mundo, que eso nos es nada nuevo pues, parafraseando a 
Keller, afirma que desde la antigüedad, y más específicamente desde la época medieval, se aplicaban prácticas para la conservación de edificios, pinturas murales, esculturas y pinturas con un enfoque de prevención del deterioro y nos recuerda que la institución responsable de recolectar, estudiar, conservar y exhibir el patrimonio cultural que forma sus colecciones es el museo, en cualquiera de sus expresiones. Castillo nos recuerda que la conservación es una actividad que, a través del tiempo, se ha convertido en una profesión científica que se dedica a mantener vivas las obras de arte, monumentos y bienes muebles que forman parte del acervo cultural de una nación o cultura.

En un artículo de singular importancia, en el marco de la actual coyuntura de nuestra sociedad, que se debate en la búsqueda de valores que encarrilen y den vitalidad a nuestra cultura, la antropóloga Concepción Clará de Guevara nos presenta un documento que titula: Tradición oral salvadoreña. Mestizaje, religión y valores. La antropóloga afirma que, en el mundo actual globalizado, se necesita urgentemente de ampliar esfuerzos en la línea de fomentar y vigorizar aquellos valores que ayuden al desarrollo y bienestar de la humanidad, sin los cuales los avances de la ciencia y la tecnología no pueden adquirir su verdadera dimensión. La antropóloga, en su artículo, sintetiza que la religión es rica en tradiciones, que se transmiten de generación en generación, y por medio de ellas, ha penetrado profundamente con valores que inciden de manera positiva en el desarrollo y bienestar de los distintos grupos humanos. Y es que, si nos fijamos en la historia de la humanidad, religión, tradiciones y valores han caminado de la mano en todas las épocas y en todas las sociedades. Desde luego que coinciden valores y tradiciones positivos y negativos en una misma sociedad. La antropóloga Concepción Clará de Guevara, finaliza su presentación afirmando que la religión necesita una amplia compresión sobre aquello que los pueblos entienden y que por medio de estas expresiones tradicionales, para reinterpretarlas y encontrar formas que beneficien los valores esenciales para introducir cambios que lleven al desarrollo del bienestar humano.

El literato salvadoreño-holandés, Ernesto Rivas Arévalo, radicado en Holanda, en un intento por entender el significado de este importante referente cultural y los estudios arqueológicos llevados a cabo a lo largo de varias temporadas de investigación en el sitio arqueológico de arte gráfico rupestre de La Pintada - gruta de arte gráfico rupestre en las riveras del río Titihuapa en el departamento de Cabañas - escribe un artículo que titula: La Pintada: Un sitio patrimonial en riesgo de desaparición. Rivas Arévalo, afirma que 
es necesario rescatar esa herencia del pasado, es necesario realizar un plan de rescate; un plan de emergencia que termine con el deterioro progresivo de La Pintada y que se prevenga su destrucción posterior.

\section{Formas y significados del vestido en una sociedad posmoderna: el caso de} San Salvador, se titula el artículo que nos ofrecen las antropólogas Mariella Hernández Moncada y Melissa Regina Campos, quienes parten que entre las formas de cultura creadas por el ser humano en la sociedad, está el modo de vestir y, a pesar de que necesidades funcionales del vestido varían de una sociedad o región a otra al encontrarse presentes en todas y cada una de ellas. Esto lo vuelve un hecho universal. Las antropólogas son de la opinión de que nuestro país alberga cada vez, un número mayor de tendencias sociales, que adoptan determinados usos y costumbres y que reflejan el deseo de las personas de diferenciarse a través de las particulares maneras de vestir en cada una de ellas. Es un artículo revelador en donde la antropología urbana está en la palestra.

El doctor Jaime Alberto López Nuila con su artículo titulado: Del descubrimiento de América: Los "tesoros" llevados a España, después del primer viaje, nos recalca que el resultado del primer viaje de Cristóbal Colón al Nuevo Mundo no produjo de regreso a Castilla, los tesoros y riquezas que todos esperaban. Permitió que el mundo científico despertara con un amplio territorio por descubrir, en el que encontrara espacio el conocimiento de la botánica, la zoología, la medicina, la cartografía, la geografía, la historia, la minería y muchos más campos de desarrollo científico, como nunca antes se había producido.

Un artículo en donde los referentes históricos y la interpretación del autor van de la mano. Por último, el arqueólogo Fabricio Valdivieso, en un artículo en donde rememora el acontecer arqueológico del país de una forma anecdótica y que titula: Remembranzas de un departamento de arqueología con los primeros arqueólogos formados en El Salvador, concluye que las intenciones de su escrito irán más allá del hecho de compartir una anécdota tras una crítica moderada, si desea verse así. Este relato aborda otras dimensiones y, entre las más importantes, sus letras esconden un llamado a la continuidad de este esfuerzo por crear ciencia en nuestro país. Pero, más importante aún, el alma de esta remembranza es en verdad un pasaje vertebral en la historia de nuestra arqueología. 
Sin más, el segundo número de Kóot es, sin lugar a duda, un aporte importante que ha reunido el producto de la investigación de acuciosos estudiosos, con el único objetivo de contribuir a la reflexión para la generación de conocimiento útil para el desarrollo de la sociedad.

\section{Dr. Ramón D. Rivas}

Editor. Revista de museología Kóot.

Museo Universitario de Antropología

Universidad Tecnológica de El Salvador

San Salvador, diciembre de 2010.

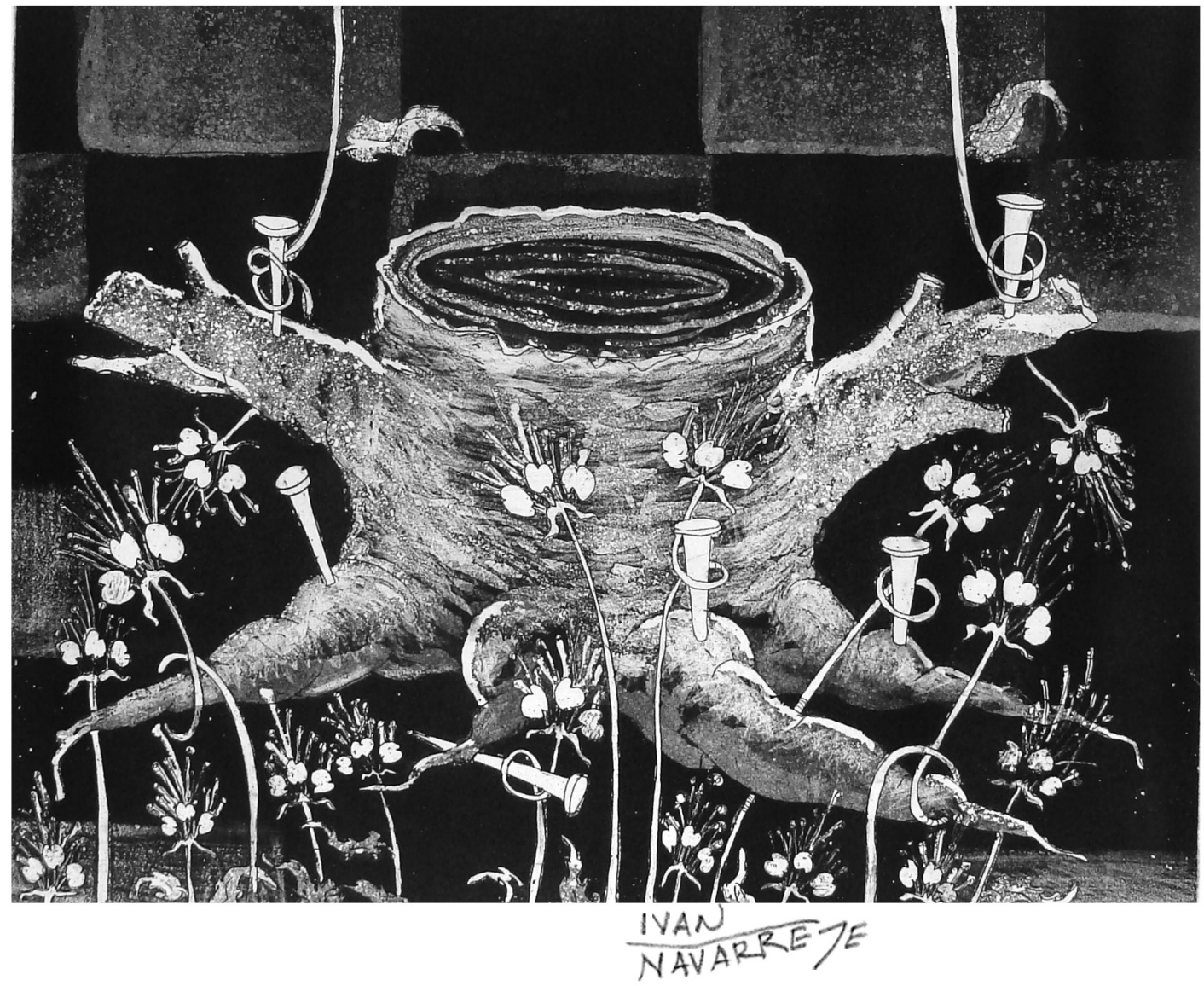

